\title{
Baseline immune profile by CyTOF can predict response to an investigational adjuvanted vaccine in elderly adults
}

\author{
Christine M. D. Lingblom ${ }^{1 \dagger}$, Sangeeta Kowli ${ }^{1 \dagger}$, Nithya Swaminathan ${ }^{2}$, Holden T. Maecker $^{{ }^{*}}$
} and Stacie L. Lambert ${ }^{2}$

\begin{abstract}
Background: Mass cytometry, or CyTOF (Cytometry by Time-of-Flight), permits the simultaneous detection of over 40 phenotypic and functional immune markers in individual cells without the issues of spectral overlap seen in traditional flow cytometry.

Methods: In this study, we applied CyTOF to comprehensively characterize the circulating immune cell populations in elderly individuals both before and after administration of an investigational adjuvanted protein vaccine against respiratory syncytial virus (RSV) in a Phase 1a trial. Antigen-specific T cell responses to RSV by IFNY ELISPOT had been observed in most but not all recipients in the highest dose cohort in this trial. Here, CyTOF was used to characterize the cellular response profile of ELISPOT responders and non-responders in this vaccine dose cohort.

Results: Both $\mathrm{CD}^{+}$and $\mathrm{CD} 8^{+} \mathrm{T}$ cell antigen-specific IFNy responses were observed. Principal components analysis revealed baseline differences between responders and non-responders, including differences in activated $\left(H L A-D R^{+}\right)$ $\mathrm{CD}^{+}$and $\mathrm{CD} 8^{+} \mathrm{T}$ cells, which were higher in non-responders versus responders. Using viSNE to analyze RSV-responsive $C D 4^{+}$and $C D 8^{+}$T cells, we also found increased expression of HLA-DR, CCR7, CD127 and CD69 in non-responders versus responders.
\end{abstract}

Conclusions: High parameter CyTOF can help profile immune components associated with differential vaccine responsiveness.

Keywords: RSV, Vaccine, CyTOF, Immune profile

\section{Background}

Aged adults have decreased immune responses compared to younger adults and are more prone to acute infections as well as reactivation of latent viruses. Waning adaptive immunity can be seen in adults as young as 50 years old [1]. Extensive research on immune senescence in the elderly has identified multiple pathways by which aging mechanisms adversely affect immune responses, particularly $\mathrm{T}$ cell responses [2-4]. Increased background

\footnotetext{
*Correspondence: maecker@stanford.edu

${ }^{\dagger}$ Christine M. D. Lingblom and Sangeeta Kowli contributed equally to this work

${ }^{1}$ Department of Immunity, Transplant, Infection, Stanford University,

Stanford, USA

Full list of author information is available at the end of the article
}

inflammation, decreased antigen presenting cell function, a higher threshold of $\mathrm{T}$ cell activation, decreased naïve $\mathrm{T}$ cell numbers, a loss of $\mathrm{T}$ cell receptor diversity, a loss of central memory CD8 T cells and reduced CD8 T cell priming are all mechanisms identified that impact $\mathrm{T}$ cell responses in older adults [5-7].

$\mathrm{T}$ cells in combination with neutralizing antibodies may have a key role in controlling respiratory viruses such as influenza and respiratory syncytial virus (RSV) that can cause more acute infections in the elderly versus healthy young adults. In an elderly adult population, $\mathrm{T}$ cell IFNY responses to influenza could distinguish between those protected by vaccination and those who subsequently developed influenza illness [8]. Pre-existing influenza-specific $\mathrm{CD} 4^{+} \mathrm{T}$ cells were 
associated with decreased illness severity following influenza challenge of healthy volunteers lacking neutralizing antibodies [9]. Though neutralizing antibody titers to RSV are similar between elderly and young adult populations [10], the elderly have decreased RSV-specific $\mathrm{T}$ cell responses compared to young adults [11, 12].

Vaccines have been only partially successful in reversing declining immune responses in older adults. Those meant for elderly subjects may benefit from inclusion of an adjuvant [13-15] or an increased antigen dose $[16,17]$. There is currently no approved vaccine for RSV though the incidence of RSV illness in older adults is on par with that of influenza illness [18]. It has been proposed that a successful vaccine for the elderly would need to induce both protective neutralizing antibodies and virus clearing T cells $[19,20]$.

An investigational adjuvanted RSV vaccine that aimed to induce both neutralizing antibodies and virus-specific $\mathrm{T}$ cells was evaluated in dose-finding Phase 1 trials in $>60$ year old subjects [21]. This vaccine consists of RSV soluble fusion protein formulated without or with the adjuvant Glucopyranosyl Lipid $A$ in $2 \%$ stable emulsion (GLA-SE). Humoral and cellular responses were measured in $>60$ year olds following vaccine dosing. At the $80 \mathrm{ug} R S V \mathrm{sF}+2.5 \mu \mathrm{g}$ GLA-SE dose tested, $100 \%$ of recipients demonstrated a $>$ threefold rise in humoral responses and $74 \%$ demonstrated a $>$ threefold rise in cellular responses [21]. A higher dose of $120 \mu \mathrm{g}$ RSV sF $+5 \mu \mathrm{g}$ GLA-SE induced similar rates of humoral and slightly higher rates of cellular immune responses [22]. The goal of the work described here was to use a targeted multiparameter evaluation of the RSV F-specific T cell response to further characterize the cellular response to RSV in these vaccinated subjects.

To more comprehensively characterize $\mathrm{T}$ cell responses to RSV, we used CyTOF mass cytometry, a highly multiparametric version of flow cytometry that uses heavy metal ion labels and mass spectrometry as the readout in lieu of fluorochromes and light detection. This methodology has the dual benefit of allowing many more specificities to be probed in parallel in the same samples, while dramatically reducing spillover between detector channels, which is a major issue in fluorescence flow cytometry [23]. Using stimulation with RSV F antigen peptides, or with Phorbol 12-myristate 13-acetate (PMA) + ionomycin, we were able to read out antigen-specific as well as global immune parameters using CyTOF, and to relate these to vaccine response as measured by enzyme-linked immune spot (ELISPOT).

\section{Methods}

\section{Human samples}

Heparinized whole blood was collected from 20 healthy older adults (60 years and older) with informed consent under an institutional review board-approved, randomized phase 1a study of MEDI7510 (NCT02115815). Demographics for this cohort are presented in Table 1. Clinical endpoints, F-specific antibody, and F-specific IFNgamma ELISPOT responses have been previously reported [21]. Samples were taken pre-vaccination, D8 and D29 post-vaccination from those subjects dosed with $80 \mu \mathrm{g}$ of soluble RSV fusion protein $\mathrm{sF}$ adjuvanted with Glucopyranosyl Lipid A in 2\% stable emulsion (GLA-SE) (Immune Design Corporation, USA). Peripheral blood mononuclear cells (PBMC) were separated by Histopaque Ficoll within $6 \mathrm{~h}$ of blood draw and cryopreserved in serum-free CTL Cryo ${ }^{\mathrm{TM}} \mathrm{ABC}$ (CTL, USA), then transferred to a central lab for $\mathrm{LN}_{2}$ storage until testing.

\section{IFNgamma ELISPOT}

Cryopreserved PBMC from study subjects were batched by subject, thawed in CTL Wash medium (Cellular Technology, USA) with benzonase nuclease (NovagenMillipore USA), washed and resuspended in CTL Test medium (Cellular Technology, USA), and tested by F-specific IFNgamma ELISPOT as previously described [24]. Briefly, viable cells were plated at 300,000 cells/well in quadruplicate in human IFNgamma ELISPOT plates (Mabtech, USA) and stimulated with either medium containing $0.1 \%$ dimethyl sulfoxide (DMSO) (mock) or $2 \mu \mathrm{g} /$ $\mathrm{mL}$ of overlapping peptide pools of RSV F (JPT GmbH, Berlin, Germany). 30,000 viable cells/well were stimulated with Staphylococcus aureus enterotoxin B (SEB) as a positive control. At 20-24 h plates were developed and counted on the ImmunoSpot Analyzer (Cellular Technology, USA). Data was expressed as the spot forming cells (SFC) per million PBMC after background subtraction of mock wells, with a lower limit of detection of $33 \mathrm{SFC} /$ million PBMC (Additional file 1).

\section{Extracellular and intracellular staining and CyTOF analysis} PBMC from study subjects as well as a healthy control sample for each batch of samples were thawed in warm CTL $10 \times$ wash medium (CTL, USA) diluted 1:10 in RPMI (Gibco-Life Technologies, USA) containing

Table 1 Demographics of study cohort

\begin{tabular}{lll}
\hline Demographic parameter & Non-responder (5) & Responder (14) \\
\hline Age (year; average \pm SD) & $70 \pm 7$ & $70 \pm 7$ \\
Age (year; range) & $62-79$ & $61-82$ \\
Female [number, (\%)] & $4,(80 \%)$ & $6,(43 \%)$ \\
\hline
\end{tabular}


L-Glutamine (Gibco-Life Technologies, USA) and Benzonase nuclease (Novagen-Millipore, USA), washed twice then resuspended in CTL test medium (CTL, USA) containing L-Glutamine, and viable cells were counted by Vicell (Merck Millipore, USA). Cells were added to a V-bottom microtiter polystyrene plate at 1 million viable cells/well, for each sample one well was kept as unstimulated, one for the RSV F peptide pool stimulation (overlapping 15-mers custom-produced by JPT, final concentration $5 \mu \mathrm{g} / \mathrm{mL}$, [24]) for $6 \mathrm{~h}$ and one for PMA/Ionomycin (Sigma-Aldrich, USA, final concentration $10 \mathrm{ng} / \mathrm{mL}$ and $1 \mu \mathrm{g} / \mathrm{mL}$, respectively) for $4 \mathrm{~h}$ at $37^{\circ} \mathrm{C}$, in a $\mathrm{CO}_{2}$ incubator. Simultaneously, activation reagent, Brefeldin A (Sigma-Aldrich, USA), and secretion inhibitor Monensin (Sigma-Aldrich, USA) was added to all the wells. PMA, Ionomycin, Brefeldin A and Monensin was diluted in CyPBS $(10 \times$ PBS without heavy metal contaminants diluted 1:10 in MilliQ water, ROCKLAND, USA). Final DMSO and ethanol concentration from all sources (peptides, brefeldin A, monensin) did not exceed $0.5 \%$. At the end of stimulation, $0.8 \mu \mathrm{L} 5 \mathrm{M}$ EDTA was added to the wells, to a final concentration of $2 \mathrm{mM}$ and incubated for $15 \mathrm{~min}$ at room temperature. The cells were washed three times with CyFACS (CyPBS with 2 mM EDTA and 0.05\% sodium azide) followed by extracellular staining for $45 \mathrm{~min}$ on ice with $70 \mu \mathrm{L}$ of the antibody cocktail (Table 2). All antibodies were either from purified unconjugated, carrier-protein-free stocks from eBiosciences, Biolegend, or R\&D Systems that we conjugated with metal isotopes ourselves or they were conjugated with metal isotopes from Fluidigm. The cells were washed three times with CyFACS buffer and then resuspended in $100 \mu \mathrm{L}$ CyPBS of 1:3000 diluted $5 \mathrm{mg} / \mathrm{mL}$ Live-Dead (1,4,7,10-tetraazacyclododecane-1,4,7,10-tetraacetic acid (DOTA)-maleimide containing natural-abundance indium 115, Macrocyclics, USA) and incubated $30 \mathrm{~min}$ on ice. The cells were washed three times with CyPBS and then resuspended in $100 \mu \mathrm{L} 2 \%$ para-formaldehyde (PFA) in CyPBS and placed at $4{ }^{\circ} \mathrm{C}$ overnight. The next day the cells were washed three times with eBioscience permeabilization buffer ( $1 \times$ in MilliQ water) followed by intracellular staining for $45 \mathrm{~min}$ on ice with $70 \mu \mathrm{L}$ of the antibody cocktail (Table 2) before washing three times with CyPBS. The cells were resuspended in $100 \mu \mathrm{L}$ iridium-containing DNA intercalator (1:2000 dilution in 2\% PFA in CyPBS; Fluidigm) and incubated at room temperature for $20 \mathrm{~min}$. The cells were washed three times in CyPBS and three times in MilliQ water. The cells were diluted in a total volume of $700 \mu \mathrm{L}$ in MilliQ water before injection into the CyTOF Helios ${ }^{\mathrm{TM}}$ (Fluidigm). The data were normalized using Normalizer
Table 2 Antibody panel for CyTOF ICS, with metal labels, clones and source

\begin{tabular}{|c|c|c|c|c|}
\hline No. & Specificity & Metal label & Clone & Source \\
\hline 1 & Live/dead & $\ln 115$ & - & In house \\
\hline 2 & CD49d & $\operatorname{Pr} 141$ & 9F10 & Fluidgm \\
\hline 3 & CD19 & $\operatorname{Nd} 142$ & HIB19 & Fluidgm \\
\hline 4 & ICOS & $\operatorname{Nd} 143$ & DX29 & Fluidgm \\
\hline 5 & CD69 & $\mathrm{Nd} 144$ & FN50 & Fluidgm \\
\hline 6 & CD4 & $\operatorname{Nd} 145$ & RPA-T4 & Fluidgm \\
\hline 7 & CD8 & $\mathrm{Nd} 146$ & SK1 & Fluidgm \\
\hline 8 & CD20 & Sm147 & $2 \mathrm{H} 7$ & Fluidgm \\
\hline 9 & CD57 & $\mathrm{Nd} 148$ & HCD57 & In house \\
\hline 10 & CD54 & Sm149 & HA58 & In house \\
\hline 11 & CD134 (OX-40) & Nd150 & АСТ35 & Fluidgm \\
\hline 12 & CD107a & Eu151 & $\mathrm{H} 4 \mathrm{~A} 3$ & Fluidgm \\
\hline 13 & TNFa & Sm152 & Mab11 & Fluidgm \\
\hline 14 & CD45RA & Eu153 & HI100 & Fluidgm \\
\hline 15 & CD3 & Sm154 & UCHT1 & Fluidgm \\
\hline 16 & CD28 & Gd155 & L283 & In house \\
\hline 17 & CD38 & Gd156 & $\mathrm{HB}-7$ & In house \\
\hline 18 & HLA-DR & Gd157 & G46-6 & In house \\
\hline 19 & CD33 & Gd158 & WM53 & Fluidgm \\
\hline 20 & CD11c & Td159 & Bu15 & Fluidgm \\
\hline 21 & CD14 & Gd160 & M5E2 & Fluidgm \\
\hline 22 & IFNY & Dy161 & $4 S . B 4$ & In house \\
\hline 23 & CD80 & Dy162 & 2D10.4 & Fluidgm \\
\hline 24 & $\mathbb{I L}-4$ & Dy163 & MP4-25D2 & Fluidgm \\
\hline 25 & $\mathbb{I L}-17$ & Dy164 & N49-653 & Fluidgm \\
\hline 26 & CD127 & Ho165 & A019D5 & Fluidgm \\
\hline 27 & $\mathrm{IL}-2$ & Er166 & MQ1-17H12 & Fluidgm \\
\hline 28 & CD27 & Er167 & L128 & Fluidgm \\
\hline 29 & CD40L & Er168 & $24-31$ & Fluidgm \\
\hline 30 & CCR7 & $\operatorname{Tm} 169$ & 15053 & In house \\
\hline 31 & PD1 & Er170 & $\mathrm{EH} 12.1$ & In house \\
\hline 32 & Granzyme B & Yb171 & GB11 & Fluidgm \\
\hline 33 & $\mathrm{NKG} 2 \mathrm{C}$ & Yb172 & 134591 & In house \\
\hline 34 & CD25 & Yb173 & M-A251 & In house \\
\hline 35 & CD16 & Yb174 & $3 G 8$ & In house \\
\hline 36 & Perforin & Lu175 & B-D48 & Fluidgm \\
\hline 37 & CD56 & Yb176 & NCAM16.2 & Fluidgm \\
\hline 38 & DNA1 & $\operatorname{lr} 191$ & - & Fluidgm \\
\hline 39 & DNA2 & Ir193 & - & Fluidgm \\
\hline 40 & CD11b & Bi209 & ICRF44 & Fluidgm \\
\hline
\end{tabular}

v0.2 MCR [25] (Additional file 2). Data analysis was performed using FlowJo v10 by gating on intact cells based on the iridium isotopes from the DNA intercalator, then on singlets by DNA intercalator versus event length, then on live cells which is the Indium-LiveDead negative population, followed by cell subset gating (Additional file 2, Fig. 2a). 


\section{Statistical analyses Multivariate analyses}

Multivariate analyses of pattern recognition "orthogonal projections to latent structures by means of partial least squares discriminant analysis" (OPLS-DA) were performed using the SIMCA-P (version 14.1) statistical package (MKS Data Analytics Solutions, Malmö, Sweden). OPLS-DA is a development of principal component analysis (PCA), in which $\mathrm{Y}$ variables are introduced and their relationship to $\mathrm{X}$ variables examined. In our case, multivariate models were created where study patients were set as Y variables (Group Y1 for non-responders and group Y2 for responders) and 29 components (cytokine responses and phenotype markers) were set as $\mathrm{X}$ variables. In the figures the 13 variables with biggest impact on the models are shown. The two-component models (PC1 and PC2) is defined by a value for explanatory power or goodness of fit, R2, which estimates the amount of variance in $\mathrm{Y}$ that is explained by the $\mathrm{X}$-variables. A high value indicates that the selected X-variables have generated a model that can explain differences that exist between the studied groups. A model is also given a value for stability, Q2, which describes the validity of the model. This is determined with cross validation, a procedure where one study subject is removed and the capacity of the remaining subjects to predict the separation between the groups is assessed. This procedure is repeated for all the subjects; a high value indicates that the model is stable no matter which subject is excluded. A number between 0 and 1 is given or $0-100 \%$. 0 being worst and 1 being best. pq1 is a value that explains the impact that the $\mathrm{X}$ variables has on the model. The program is set to mean centering and unit variance scaling to give all variables an equal chance of providing model leverage independently of data scale and distribution.

\section{viSNE (visual high-dimensional single-cell data analysis based on the t-Distributed Stochastic Neighbor Embedding (t-SNE) algorithm)}

viSNE is a dimensionality reduction algorithm that permits visualization of multi-dimensional data as a two dimensional scatter plot. We performed viSNE analysis in cytobank (Cytobank, Santa Clara, CA). Boolean 'OR' gates for CD107a, IFN $\gamma$, TNF $\alpha$ and IL-4 from responders $(n=14)$ and non-responders $(n=5)$ were concatenated in FlowJo v10.1 for both $\mathrm{CD}^{+}$and $\mathrm{CD}^{+} \mathrm{T}$ cells after RSV (F) peptide stimulation at day 0 and day 8. For comparative analysis, samples were down sampled and viSNE maps were generated from a mixture of equal-sized samples $\left(C D 4^{+} \mathrm{T}\right.$ cells $=30,205$ events per sample; $\mathrm{CD} 8^{+} \mathrm{T}$ cells $=10,437$ events per sample). The event count for each $\mathrm{T}$ cell population was determined by the sample with the lowest events. After importing the concatenated files into cytobank, viSNE was run using default cytobank parameters (iterations $=1000$, perplexity $=30$ and theta $=0.5)$. In each figure, all samples were derived from the same viSNE run. viSNE maps show median marker expression for each population. Scales on the maps are individually generated for each marker with the intensity levels from low (blue) to high (red) expression.

\section{Univariate analyses}

Unpaired $t$ test was used to determine statistical significance between the study subjects on day 0 and day 8 as well as on day 0 and day 29. GraphPad Prism 7.0 was used to plot graphs (GraphPad, San Diego, CA, USA).

\section{Results}

T cell responses by IFN $\gamma$ ELISPOT

As previously reported, pre- and post-vaccination PBMC obtained from the clinical trial participants were tested for $\mathrm{T}$ cell responses by a qualified F-specific IFN $\gamma$ ELISPOT assay, with a peak response at Day 8 post vaccination [21]. A minimum threefold change in F-specific responses at Day 8 versus pre-vaccination was used to designate responders by this assay. Among the 20 subjects in the treatment cohort, one subject was dropped as the PBMC viability was low and the sample failed the acceptance quality criteria for the F-specific IFN $\gamma$ ELISPOT assay. Of the 19 subjects with reportable data for both the prevaccination and Day 8 timepoints, 14 subjects demonstrated $\mathrm{a} \geq$ threefold rise in responses, with responses ranging from 4.3- to 32.2-fold over baseline (Fig. 1). 5 subjects with $\mathrm{a}<$ threefold rise in responses were designated as non-responders. These ELISPOT responses were used to categorize the vaccine subjects for subsequent multiparameter intracellular cytokine staining by CyTOF analysis. Cytomegalovirus (CMV) status is unknown for the study subjects; CMV may affect T cell response rates to other antigens.

\section{CyTOF analysis and detection of RSV-specific T cell responses}

A representative manual gating schema used to identify major peripheral blood subsets including B cells, $\mathrm{CD} 4^{+}$ and $C D 8^{+} \mathrm{T}$ cells, NK cells and monocytes is shown in Fig. 2a. While the percentage of $\mathrm{CD}^{+} \mathrm{CD} 4^{+} \mathrm{T}$ cells was slightly higher in the non-responders compared to the responders (Additional file 3A), no significant differences were found in either the $\mathrm{CD}^{+} \mathrm{CD}^{+}$or $\mathrm{CD}^{+} \mathrm{CD}^{+} \mathrm{T}$ cell percentages between responders and non-responders, pre-vaccine or on day 8 or 29 post-vaccine (Additional file $3 \mathrm{~A}, \mathrm{~B})$. Figure $2 \mathrm{~b}$ is a representative dot plot showing the induction of $\mathrm{CD}^{+}{ }^{+} \mathrm{IFN}^{+}$and $\mathrm{CD}^{+}{ }^{+} \mathrm{TNF}^{+}$ after stimulation with RSV s(F) pp on D8. 


\section{ELISPOT responses Day 8}

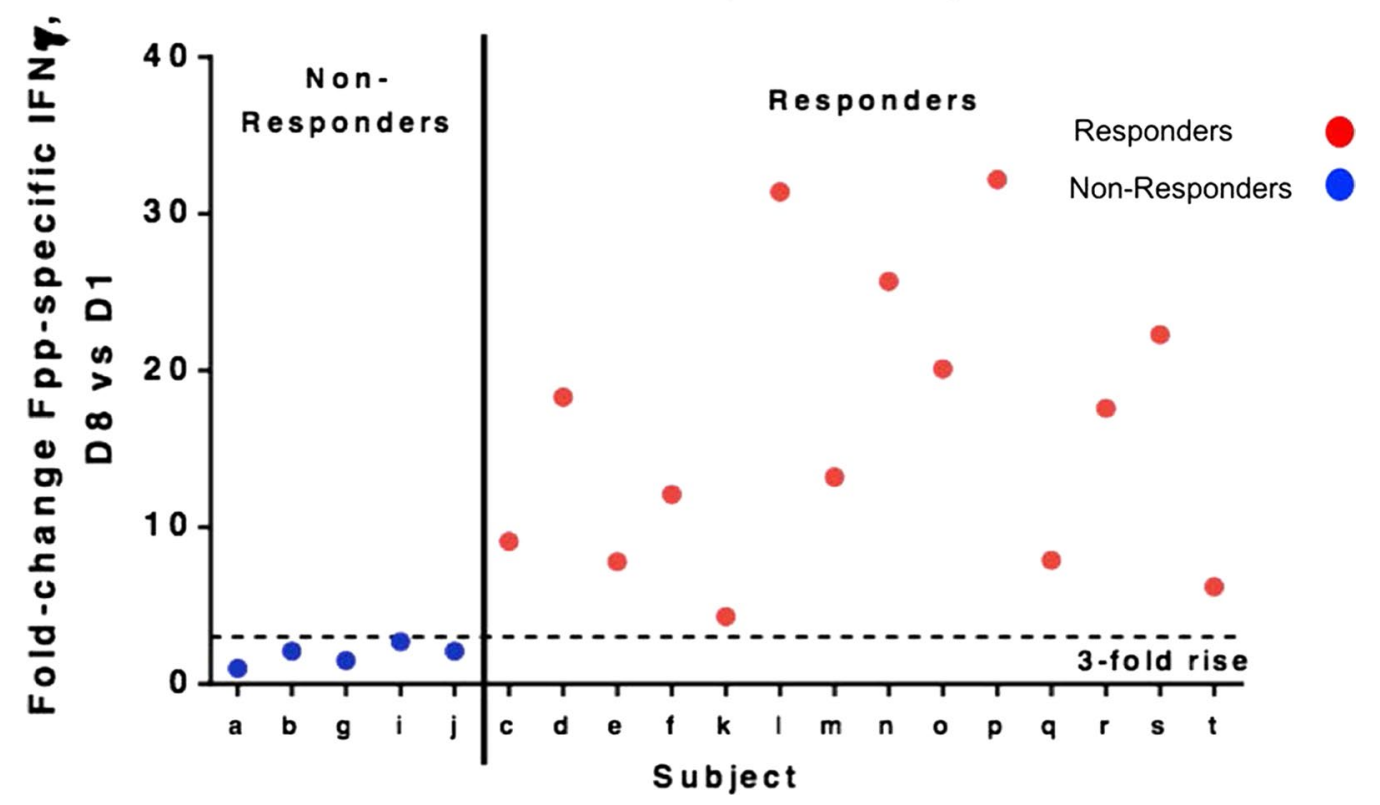

Fig. $1 \mathrm{IFNY}^{+}$ELISPOT responses, Day 8 vs Day 1. A threefold rise was declared as a responder

\section{Th1 versus Th2 responses}

To determine the effects of RSV $\mathrm{s}(\mathrm{F})$ pp on Th1 and Th2 responses between responders and non-responders, levels of IFN $\gamma$ and IL-4 were independently assessed by manual gating in FlowJo. RSV $\mathrm{s}(\mathrm{F})$ pp stimulation resulted in both $\mathrm{CD}^{+}$and $\mathrm{CD}^{+}$IFN $\gamma$ responses, and $\mathrm{CD}^{+}{ }^{+}$IL-4 responses (Fig. $3 \mathrm{a}-\mathrm{C}$ ). An upward trend was observed in the responders for both $\mathrm{CD}^{+}$and $\mathrm{CD}^{+}$ $\mathrm{IFN}^{+}{ }^{+}$and $\mathrm{CD}_{4}^{+} \mathrm{IL}^{-} 4^{+}$at D8 and D29 compared to D0. Furthermore, we observed significantly higher baseline levels of $\mathrm{CD}^{+}$IFNy in the non-responders compared to the responders at D0 (before vaccination) (Fig. 3b). A gradual increase in the frequency of IL- $4^{+}$producing $\mathrm{CD}^{+} \mathrm{T}$ cells post-stimulation with $\mathrm{RSV} \mathrm{s}(\mathrm{F}) \mathrm{pp}$ was also seen in the responders (Fig. 3d).

\section{Longitudinal patterns of cytokine responses}

To evaluate the multifunctionality of $\mathrm{CD}_{4}^{+}$and $\mathrm{CD}^{+}$ $\mathrm{T}$ cells in response to RSV, we assessed the expression of $\mathrm{TNF} \alpha^{+}, \mathrm{IFN} \gamma^{+}, \mathrm{IL}-2^{+}, \mathrm{IL}-4^{+}, \mathrm{IL}-17^{+}$as well as dual- and tri-cytokine positive combinations pre-(day 0 ) and post-vaccination (day 8 and day 29). Shown here are the top three responders. The average of day 8 and day 29 boolean 'OR' gates for $\mathrm{IFN}^{+}, \mathrm{TNF}^{+}, \mathrm{IL}^{+}{ }^{+}$, $\mathrm{IL}-4^{+}$, IL- $17^{+}$expression was used to determine the top three responders. In subject 1 , IFN $\gamma^{+}$expression is dominant at baseline. Post-vaccination on day 8 and day 29, $\mathrm{TNF}^{+}$expression as well as the proportion of dual IFN $\gamma^{+} \mathrm{TNF}^{+} \mathrm{CD}^{+}{ }^{+} \mathrm{T}$ cells is markedly upregulated (Fig. 4a, top panel). In subject o, the proportion of $\mathrm{IL}-17^{+} \mathrm{CD} 4^{+} \mathrm{T}$ cells is dominant pre- and post-vaccination. We also find that the expression of $\mathrm{TNF}^{+}$ and $\mathrm{IFN}^{+} \mathrm{CD}^{+} \mathrm{T}$ cells reduces slightly post-vaccination on day 8 compared to pre-vaccination (day 0 ) but increases post-vaccination on day 29 to levels comparable to pre-vaccination (day 0) (Fig. 4a, middle panel). In subject $r$, pre-vaccination (day 0 ) the proportion of IL-4 ${ }^{+}$CD $4^{+} \mathrm{T}$ cells is most dominant. However, postvaccination on day 8 and day 29 we observe a switch from IL- $4^{+} \mathrm{CD} 4^{+} \mathrm{T}$ cells to $\mathrm{TNF} \alpha^{+}$and $\mathrm{IFN}^{+} \mathrm{CD}^{+}{ }^{+} \mathrm{T}$ cells (Fig. $4 \mathrm{a}$, bottom panel). In $\mathrm{CD}^{+} \mathrm{T}$ cells, post-vaccination in subject 1 , the cytokine production switches from $\mathrm{IL}_{-}-17^{+}$(day 0) primarily to $\mathrm{IFN} \gamma^{+}$at day 8 and day 29 (Fig. 4b, top panel). In subject o, IL- $17^{+}$production is dominant both pre-(day 0$)$ and post-vaccination (day 8 and day 29) (Fig. 4b, middle panel). In subject $r$, post-vaccination (day 29), induced $\mathrm{TNF}^{+} \mathrm{CD}^{+} \mathrm{T}$ cells as well as dual- and tri-cytokine positive $\mathrm{CD}^{+}$ $\mathrm{T}$ cells (Fig. 4b, bottom panel). These results suggest that first, there is substantial heterogeneity in cytokine production among the subjects. Second, pre- and postvaccination, single cytokine production is dominant compared to the contribution from dual- or tri-positive cytokines both in $\mathrm{CD}^{+}$and $\mathrm{CD}^{+} \mathrm{T}$ cells. In general, the proportion of the single cytokine population prevalent for any given subject pre-vaccination (day 0) 


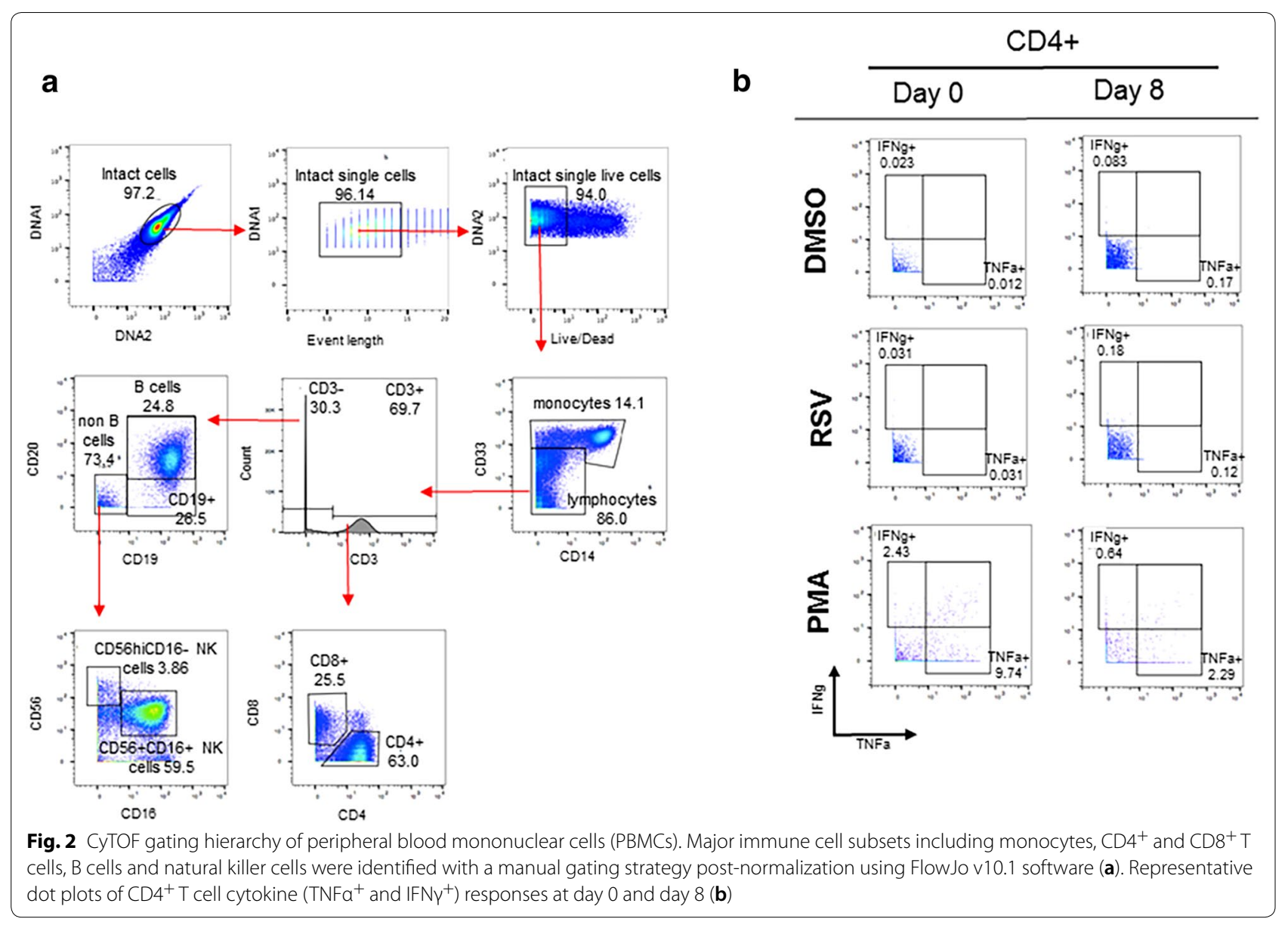

does not dramatically change post-vaccination (day 8 and day 29).

\section{Principal components analysis of RSV-specific T cell responses}

The multivariate method of OPLS-DA was used to see if it was possible to predict the outcome of the vaccine based on the immune profile of the patients at baseline. We divided the patients into two groups, responders $(R)$ and non-responders (NR), based on the results from the IFN $\gamma$ ELISPOT (Fig. 1). The cytokine responses as well as surface marker levels after RSV stimulation at baseline (day 0 ) were set as study variables $(\mathrm{X})$ and the two study groups were set as outcome variables $(\mathrm{Y})$. The two study groups formed two distinct clusters, a tight one composed of responders and a scattered one composed of non-responders (Fig. 5a). When we constructed a loading plot to see which variables that contributed to the separation, interestingly, the non-responders were positively associated with $\mathrm{CD} 4^{+} \mathrm{HLA}-\mathrm{DR}^{+} \mathrm{CD} 38^{-}$ and $\mathrm{CD}^{+} \mathrm{HLA}-\mathrm{DR}^{+} \mathrm{CD} 38^{-}$and the responders with CD $4^{+} \mathrm{HLA}_{-\mathrm{DR}}{ }^{-} \mathrm{CD} 38^{-}$and $\mathrm{CD} 8^{+} \mathrm{HLA}^{-} \mathrm{DR}^{-} \mathrm{CD} 38^{-}$.
We also found that non-responders had higher levels of $\mathrm{CD}^{+}{ }^{+} \mathrm{CD} 9^{+}, \mathrm{CD}^{+} \mathrm{IFN}^{+}$and non-B-cells at baseline and responders had higher levels of $\mathrm{CD}^{-} \mathrm{CD} 19^{+}$and $\mathrm{B}$ cells (Fig. 5b). The generated model had a stability of $44 \%$ $(\mathrm{Q} 2 \mathrm{Y}=0.44)$ and explanatory power of $66 \%$ (a goodness of fit $\mathrm{R} 2 \mathrm{Y}=0.66$ ).

\section{viSNE analysis of RSV-specific $T$ cell responses}

To determine differences in antigen-specific $\mathrm{CD} 4^{+}$ and $\mathrm{CD}^{+} \mathrm{T}$ cells between responders and nonresponders, we performed viSNE analysis. For each participant, boolean 'OR' gates on RSV specific $\mathrm{CD} 107 \mathrm{a}^{+} \mathrm{IFN} \gamma^{+} \mathrm{TNF} \alpha^{+} \mathrm{IL} 4^{+} \mathrm{CD} 4^{+}$and $\mathrm{CD} 8^{+} \mathrm{T}$ cells preand post-vaccination (day 0 and day 8 , respectively) were generated in flowjo v10.1. The individual fcs files for the boolean gates were then concatenated into single standard fcs files for responders and non-responders, resulting in a total of 4 concatenated files for each $\mathrm{T}$ cell population (Additional file 4). Using Cytobank software, the viSNE algorithm analysed ungated cell populations for equal number of events per time point for each $T$ cell population (as described above in MM). viSNE plots are shown 


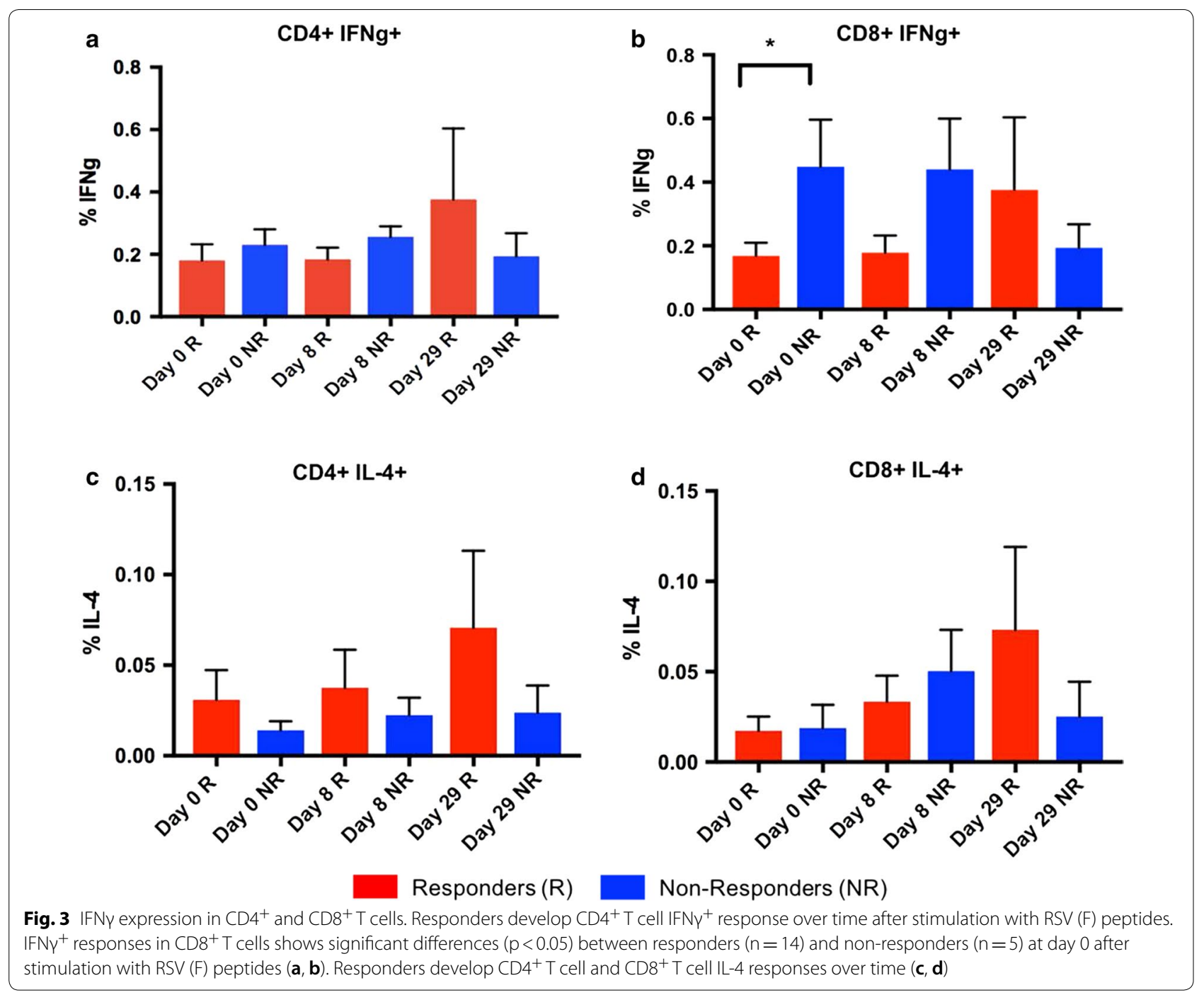

as two-dimensional scatter plots with the $\mathrm{x}$ - and $\mathrm{y}$-axes identified by tSNE1 and tSNE2. Each dot on the plot represents a single cell positioned according to similarity in the high-dimensional space. For comparative purposes, viSNE on pre- and post-vaccinated days (Day 0 and Day 8) between responders and non-responders for each $T$ cell population was performed in the same run. For both $\mathrm{CD}^{+}{ }^{+}$(Fig. 6a) and $\mathrm{CD}^{+}$(Fig. 6b) T cell populations, viSNE analysis showed an increased expression of HLA$\mathrm{DR}^{+}, \mathrm{CD} 127^{+}, \mathrm{CCR}^{+}$and $\mathrm{CD}^{+} 9^{+}$cells in responders and non-responders post-vaccination (day 8) compared to baseline (day 0). Furthermore, the expression of $\mathrm{CD}_{4}^{+}$ and $\mathrm{CD}^{+}{ }^{+} \mathrm{HLA}_{-\mathrm{DR}}{ }^{+}, \mathrm{CD}_{127^{+}}, \mathrm{CCR}^{+}$and $\mathrm{CD} 69^{+}$ cells was higher in the non-responders compared to the responders both pre- and post-vaccination (day 0 and day 8 , respectively). Interestingly, for both $\mathrm{CD} 4^{+}$and $\mathrm{CD} 8^{+} \mathrm{T}$ cells, viSNE identified the same population of cells. The pattern of expression was similar but the intensity levels was different for all the markers. Again, the findings from PCA corroborate with some of the viSNE results, with $\mathrm{CD} 4^{+} \mathrm{HLA}^{-\mathrm{DR}}{ }^{+}, \mathrm{CD} 4^{+} \mathrm{CD} 69^{+}, \mathrm{CD} 8^{+} \mathrm{HLA}-\mathrm{DR}^{+}$, $\mathrm{CD}^{+}{ }^{+} \mathrm{CCR} 7^{+}$being positively co-related with the nonresponders (Fig. 5b).

\section{Discussion}

In this study, we successfully derived baseline cellular features from our CyTOF analyses that were associated with ELISPOT response to an experimental RSV vaccine. Notable among these features were high baseline levels of IFN $\gamma$-producing RSV-specific $\mathrm{CD}^{+} \mathrm{T}$ cells, which were associated with non-responder status. In the setting of influenza vaccination, a high baseline titer of hemagglutinin-inhibiting (HI) antibodies has been linked to lower fold-change in $\mathrm{HI}$ antibodies post-vaccination [26]. A similar relationship has been found for $\mathrm{CD} 4^{+} \mathrm{IFN} \gamma^{-}$producing $\mathrm{T}$ cells specific to influenza [27]. 

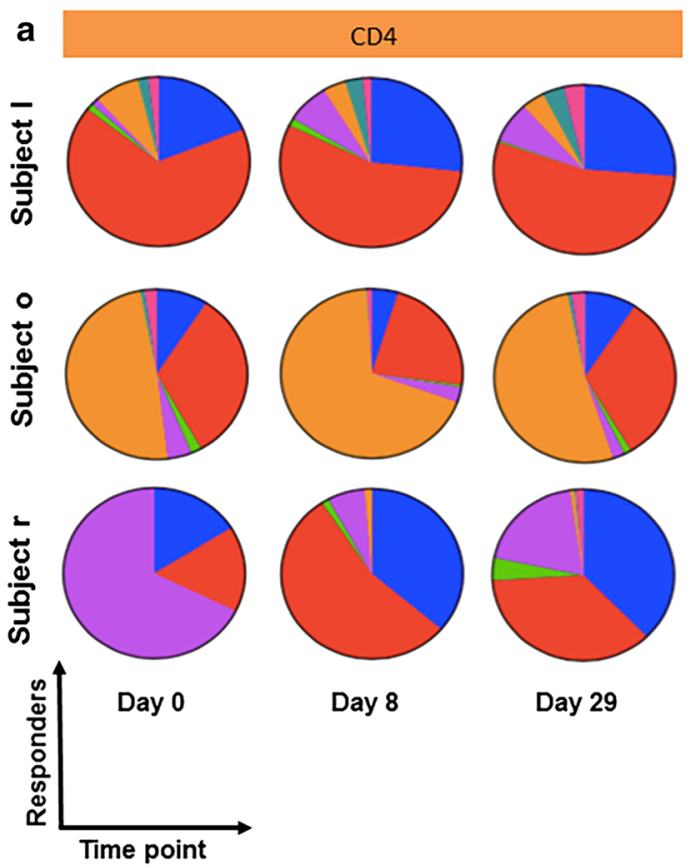

Day 8

Day 29 b
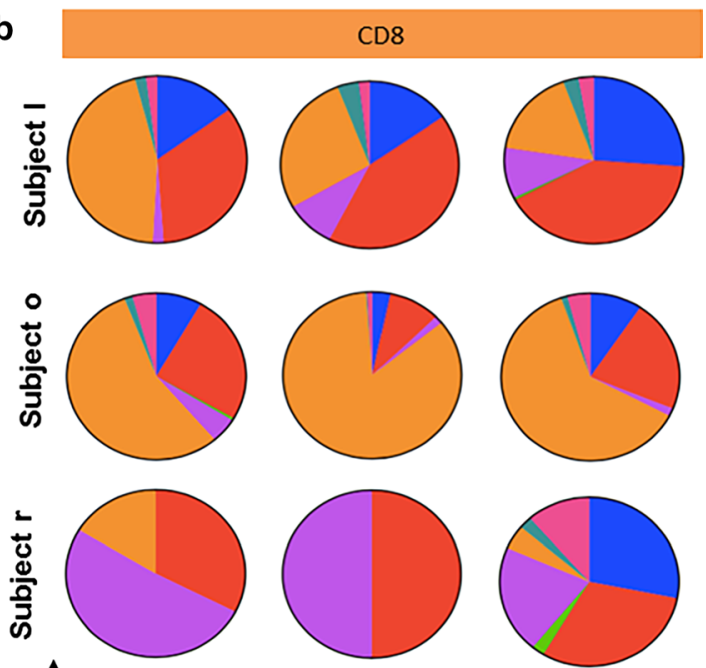

Day 8

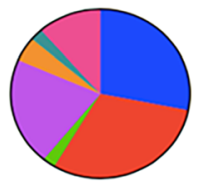

Day 29

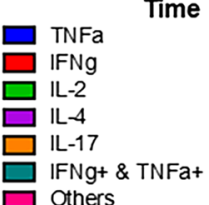

Fig. 4 Multifunctional analysis of $C D 4^{+}$and $C D 8^{+} T$ cell cytokine responses to RSV. Day 8 and day 29 boolean 'OR' gates for $C D 4^{+}$and $C D 8^{+} T$ cell IFNY ${ }^{+}, \mathrm{TNFa}^{+}, \mathrm{IL}-2^{+}, \mathrm{IL}-4^{+}$and $\mathrm{IL}-17^{+}$expression in response to RSV (F) peptide stimulation, were generated in Flowjo 10.1. The average of the boolean 'OR' gates was used to determine the top three responders. Multifunctional analysis revealed heterogeneity in cytokine production among the subjects as well as dominance of single cytokine production both pre- and post-vaccination compared to dual- or tri-CD4 ${ }^{+}(\mathbf{a})$ and $\mathrm{CD} 8^{+}(\mathbf{b})$ positive cytokines

Our findings with this experimental RSV vaccine may be related, in that it may be more difficult to boost a preexisting immune response with vaccination. As Falloon et al. concluded, a correlate of protection from RSV is yet unknown, and while both antibodies and $\mathrm{T}$ cells were induced by vaccination these did not provide protection [22].

We also saw an association of activated (HLA-DR ${ }^{+}$) $\mathrm{CD}^{+}$and $\mathrm{CD}^{+} \mathrm{T}$ cells with non-responder status. While the short term in vivo exposure to antigen should be too short to induce HLA-DR expression, these cells might indicate the level of chronic inflammation in these elderly subjects. Chronic inflammation in the elderly is considered a cause of immunologic aging [28]. Higher levels of inflammatory response transcripts have been linked with hypo responsiveness to hepatitis B vaccination [29].

The PCA-model revealed two study groups that formed two distinct clusters, a tight one composed of responders and a scattered one composed of non-responders. The results indicates that responders have a more homogenous and "healthy" phenotype before vaccination whereas non-responders do not. The different profiles explain why we see 9 variables associated with nonresponders and only 4 variables associated with responders in the loading plot. Consequently, if a patient has increased levels of any of these 9 variables the outcome of the vaccine against RSV may be poor. A number of features from the PCA-model displayed excellent correlation with the viSNE analysis. High levels of $\mathrm{CD} 4^{+} \mathrm{HLA}-\mathrm{DR}{ }^{+}$, $\mathrm{CD} 4^{+} \mathrm{CD} 9^{+}, \mathrm{CD} 8^{+} \mathrm{HLA}-\mathrm{DR}^{+}, \mathrm{CD} 4^{+} \mathrm{CCR} 7^{+}$at baseline were associated with non-responders using both statistical methods. These variables were among the nine variables with the highest discriminatory power in the PCA model.

Surprisingly, our univariate analysis revealed that only $\mathrm{CD}^{+} \mathrm{IFN} \gamma^{+}$were statistically significant between responders and non-responders at baseline, although, a trend was observed at day 8 . We could also see a minor increase for responders when comparing day 0 and day 29 for $\mathrm{CD}^{+} \mathrm{IFN}^{+}, \mathrm{CD} 4^{+} \mathrm{IL} 4^{+}$and $\mathrm{CD} 8^{+} \mathrm{IL}^{+}$. Although 


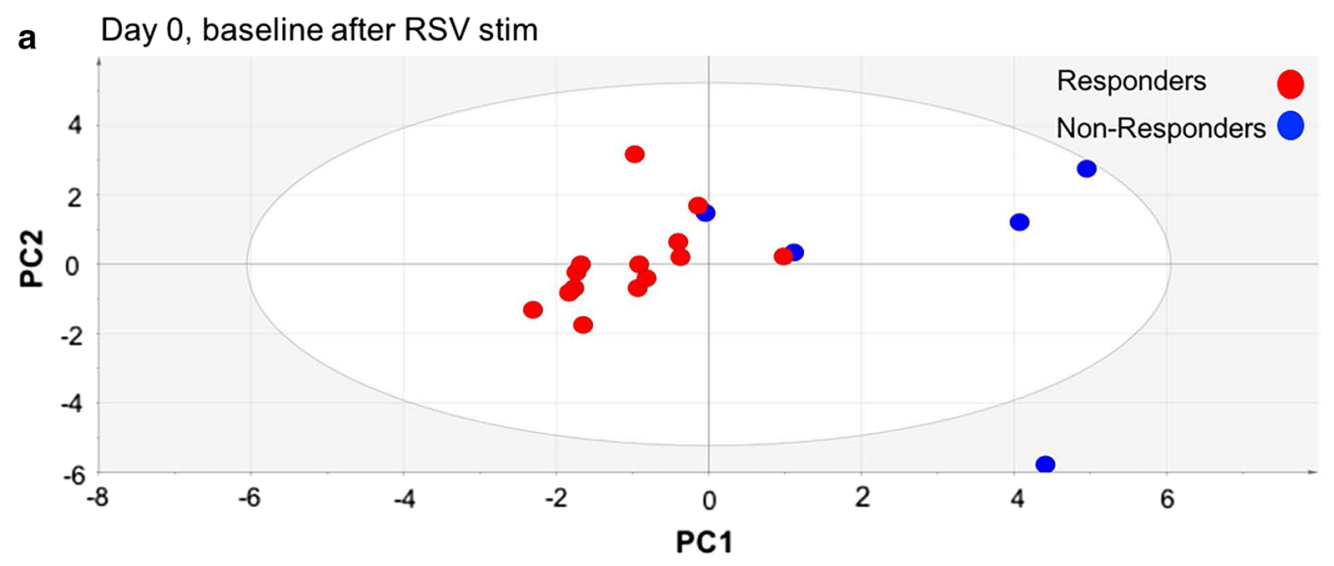

b Day 0, baseline after RSV stim

$1 . \mathrm{R} 2=0.66$

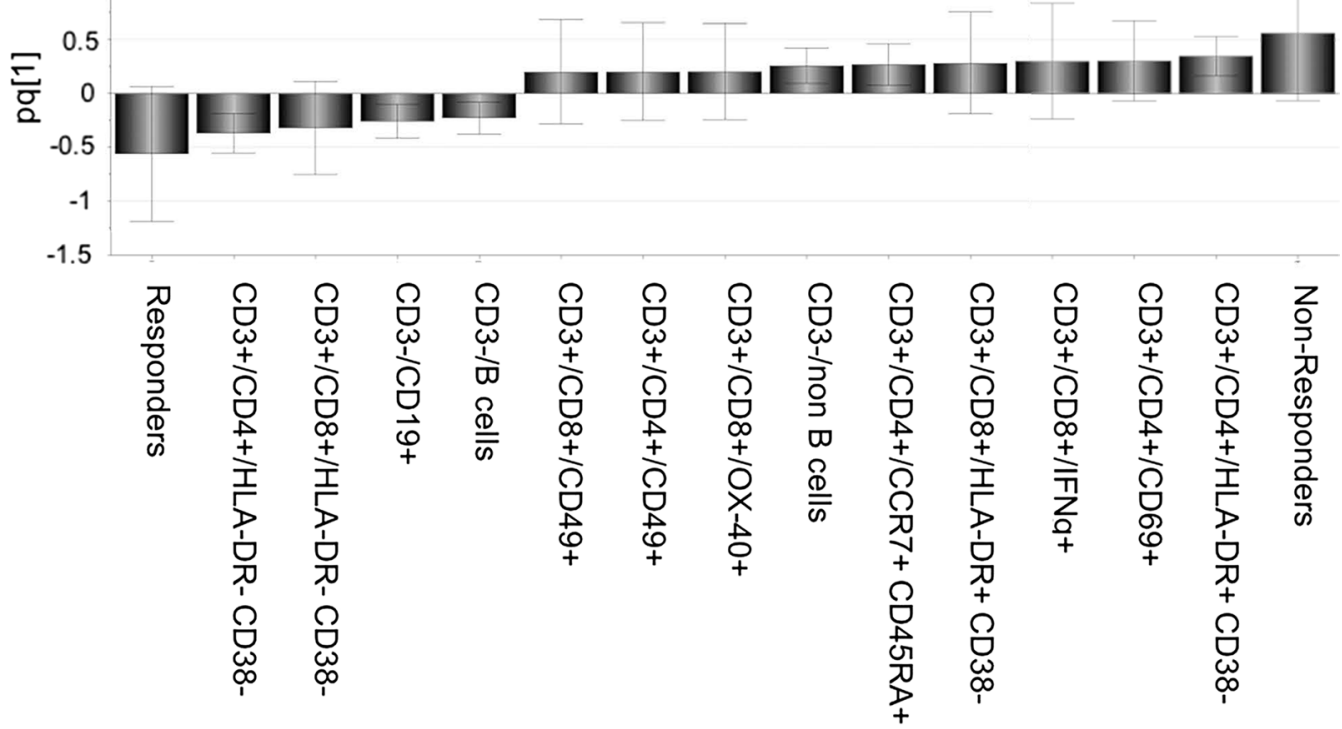

Fig. 5 PCA analysis on gated subsets. a Multivariate analysis of cytokine responses and phenotype marker levels in the study groups at day 0 , before vaccination. "Orthogonal partial least square-discriminant analysis" (OPLS-DA) was done to see if the cytokine responses and markers (X-variables) could segregate the two study groups ( $Y$-variables, e.g. non-responders $(n=5)$ and responders $(n=14)$ before vaccine against RSV was given. The generated model had a stability of $44 \%(Q 2 Y=0.44$ ) and explanatory power of $66 \%$ (a goodness of fit R2Y $=0.66)$. $\mathbf{b}$ Column graph of the OPLS-DA was done to see which variables had the largest impact on the separation of the two groups (responders and non-responders at day 0 ).

Variables closest to the subject group are positively associated

this did not reach statistically significance, this was not seen for non-responders.

Among subjects with the highest responses (shown in the pie charts), a single cytokine seemed to dominate while the proportions were not greatly changed by vaccination, with the exception of IL-4 in the majority of pies and IL-17 as well as IFNY in some pies. Interestingly, we could see a wide heterogeneity among the donors; different subjects have different cytokines that dominate in their immune profile, and in general, the same cytokine dominated before and after vaccination. The time point post vaccination were not optimal for studying innate immune cells, therefor we directed our attention to adaptive immune cells.

Possibly, the already activated state in non-responders makes it harder for their immune system to react again, as we previously discussed, and would benefit from a higher dose. If one could produce a more effective vaccine based on the immune profile of the subject perhaps immunosenescence would no longer 


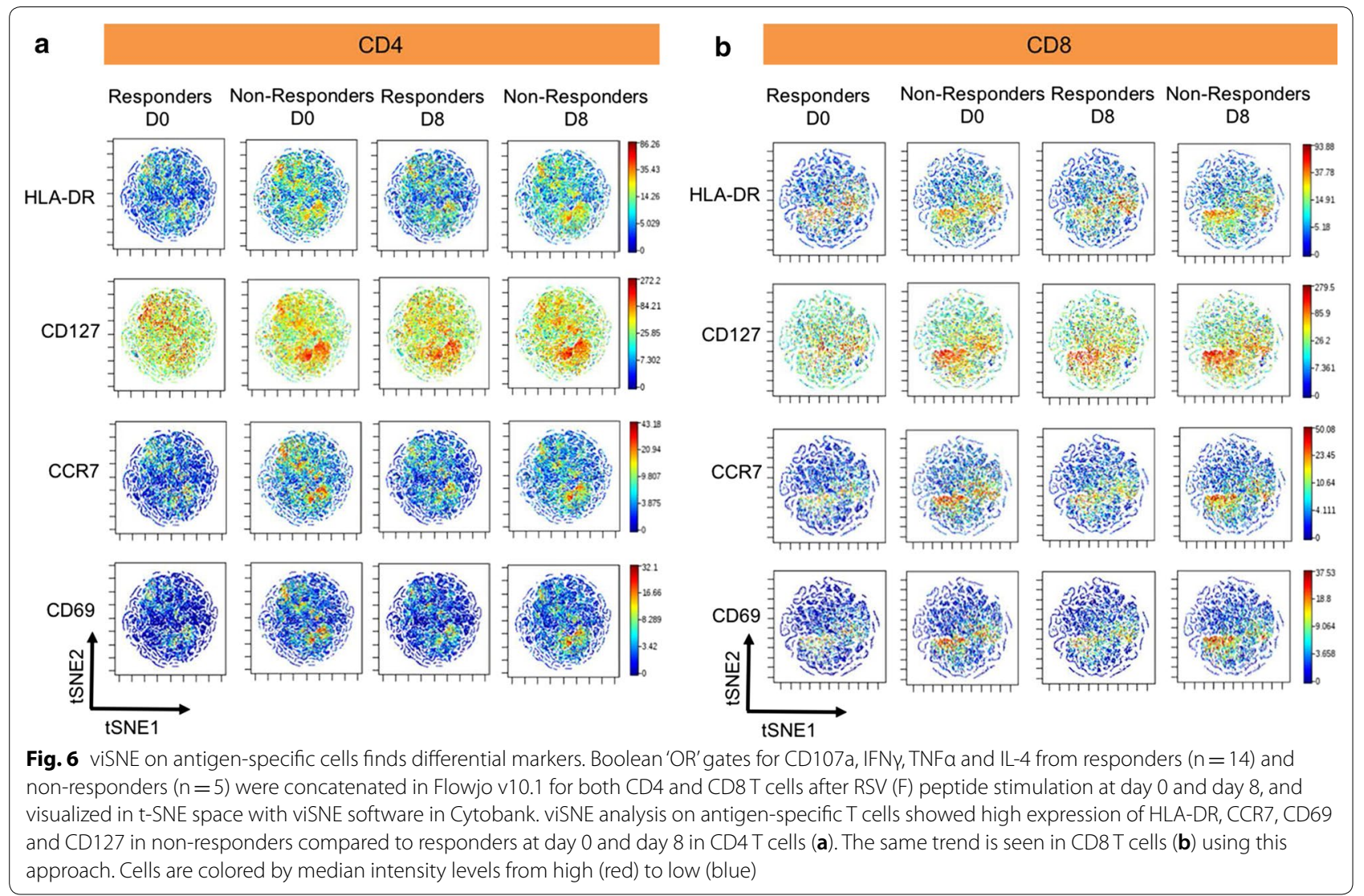

be a determining factor for vaccine response. In addition, the huge economic cost for the society associated with elderly not responding to vaccines, resulting in increased medical care, increased use of medicines and lost time at work would benefit from vaccines that are designed after the immune profile of the subject at baseline. The elderly population [30] is increasing and finding vaccines and other pharmaceuticals suited for that expanding group is becoming substantially more important.

In this study, we demonstrate the advantage of combining vaccine studies with mass cytometry. It enables an understanding of the complex immune response that is difficult to obtain with other methods. Here, it specifically revealed how elderly responded to vaccines based on their baseline cellular features. With this highdimensional technique, co-expression of cytokines can be studied in several cell types and subgroups in a single sample. As such, it helps us to paint a wider picture of the immune system. A challenging task is to process the large amounts of generated data and interpret it correctly. Therefore, it is essential to use multivariate analysis, e.g., PCA and viSNE, as we do in this study. As mass cytometry as well as more advanced multivariate methods are getting more available in vaccine research, we will be able to get a clearer picture and enhanced understanding of both immunosenescence and vaccine response.

\section{Conclusion}

Our results show the impact of individual immune profiles on successful RSV-vaccine immune response. As our knowledge of the immune system increases, we believe this is a factor that needs to be accounted for when designing vaccines in the future. Taken together, our findings demonstrate the potential of CyTOF as a powerful technology that permits comprehensive profiling of immune components, thereby enabling prediction of responses to vaccines.

\section{Additional files}

Additional file 1. Mock subtracted IFNy responses at Day 1, at Day 8 undepleted, CD4 depleted and CD8 depleted.

Additional file 2. CyTOF workflow.

Additional file 3. Percentage of RSV specific $\mathrm{CD}^{+} \mathrm{CD}^{+}$and $\mathrm{CD} 3^{+} \mathrm{CD} 8^{+}$ responses.

Additional file 4. Workflow to perform viSNE analysis on antigen-specific cells. 


\begin{abstract}
Abbreviations
CyTOF: Cytometry by Time-of-Flight; RSV: respiratory syncytial virus; ELISPOT: The Enzyme-Linked ImmunoSpot; GLA-SE: Glucopyranosyl Lipid A in 2\% stable emulsion; PBMC: peripheral blood mononuclear cells; SFC: spot forming cells; DMSO: dimethyl sulfoxide; SEB: Staphylococcus aureus enterotoxin B; PMA: Phorbol 12-myristate 13-acetate; PFA: paraformaldehyde; CMV: cytomegalovirus; DOTA: 1,4,7,10-tetraazacyclododecane-1,4,7,10-tetraacetic acid; PCA: principal components analysis; OPLS-DA: orthogonal partial least square-discriminant analysis; viSNE: visualization tool for high-dimensional single-cell data based on the t-Distributed Stochastic Neighbor Embedding (t-SNE) algorithm; HI: hemagglutin-inhibiting.
\end{abstract}

\section{Authors' contributions}

$\mathrm{CL}$ performed the experimental portions, CL and SK performed statistical analysis, CL and NS performed studies to establish stimulation conditions, SL conceived of and designed the study, all authors participated in study revisions, data interpretation, drafting and revising the article for important intellectual content. All authors read and approved the final manuscript.

\section{Author details}

1 Department of Immunity, Transplant, Infection, Stanford University, Stanford, USA. ${ }^{2}$ Translational Sciences, Medlmmune, Mountain View, CA, USA.

\section{Acknowledgements}

Authors wish to acknowledge the Ph1a subjects, Ph1a clinical sites (Miami Research Associates, Compass Research, and Accelovance) and key Medlmmune individuals involved in Ph1a study design and operation: Judy Falloon, Kristin Kopacz, Mark Esser, and Tonya Villafana.

\section{Competing interests}

The authors declare that they have no competing interests.

\section{Availability of data and materials}

The datasets used and analyzed during the current study are available from the corresponding author on reasonable request.

\section{Consent for publication}

\section{Not applicable.}

\section{Ethics approval and consent to participate}

The clinical protocol was approved by relevant institutional review boards or ethics committees. All subjects provided written informed consent. This study was conducted in accordance with the Declaration of Helsinki and good clinical practice guidelines. This study did not involve the use of any animal.

\section{Funding}

Funding was provided by Medlmmune, a subsidiary of AstraZeneca.

\section{Publisher's Note}

Springer Nature remains neutral with regard to jurisdictional claims in published maps and institutional affiliations.

Received: 12 February 2018 Accepted: 28 May 2018

Published online: 05 June 2018

\section{References}

1. Goronzy JJ, Weyand CM. Understanding immunosenescence to improve responses to vaccines. Nat Immunol. 2013;14:428-36. https://doi. org/10.1038/ni.2588.

2. Goronzy JJ, Weyand CM. Successful and maladaptive T cell aging. Immunity. 2017:46:364-78. https://doi.org/10.1016/j.immuni.2017.03.010.

3. Wertheimer AM, Bennett MS, Park B, Uhrlaub JL, Martinez C, Pulko V, et al. Aging and cytomegalovirus infection differentially and jointly affect distinct circulating T cell subsets in humans. J Immunol. 2014;192:2143-55. https://doi.org/10.4049/jimmunol.1301721.

4. Palmer DB. The effect of age on thymic function. Front Immunol. 2013;4:316. https://doi.org/10.3389/fimmu.2013.00316.
5. Britanova OV, Putintseva EV, Shugay M, Merzlyak EM, Turchaninova MA, Staroverov DB, et al. Age-related decrease in TCR repertoire diversity measured with deep and normalized sequence profiling. J Immunol. 2014;192:2689-98. https://doi.org/10.4049/jimmunol.1302064.

6. Yan J, Greer JM, Hull R, O'Sullivan JD, Henderson RD, Read SJ, et al. The effect of ageing on human lymphocyte subsets: comparison of males and females. Immun Ageing. 2010;7:4. https://doi. org/10.1186/1742-4933-7-4.

7. Briceño O, Lissina A, Wanke K, Afonso G, von Braun A, Ragon K, et al. Reduced naïve CD8(+) T-cell priming efficacy in elderly adults. Aging Cell. 2016;15:14-21. https://doi.org/10.1111/acel.12384.

8. McElhaney JE, Xie D, Hager WD, Barry MB, Wang Y, Kleppinger A, et al. T cell responses are better correlates of vaccine protection in the elderly. J Immunol (Baltimore, Md : 1950). 2006;176:6333-9.

9. Wilkinson TM, Li CKF, Chui CSC, Huang AKY, Perkins M, Liebner JC, et al. Preexisting influenza-specific $\mathrm{CD}^{+}{ }^{+} \mathrm{T}$ cells correlate with disease protection against influenza challenge in humans. Nat Med. 2012;18:274-80. https://doi.org/10.1038/nm.2612.

10. Falsey AR, Walsh EE, Looney RJ, Kolassa JE, Formica MA, Criddle MC, et al. Comparison of respiratory syncytial virus humoral immunity and response to infection in young and elderly adults. J Med Virol. 1999:59:221-6. https://doi.org/10.1002/ (SICI) 1096-9071(199910)59:2<221:AID-JMV16>3.0.CO;2-H

11. Cherukuri A, Patton K, Gasser RA, Zuo F, Woo J, Esser MT, et al. Adults 65 years old and older have reduced numbers of functional memory $T$ cells to respiratory syncytial virus fusion protein. Clin Vaccine Immunol. 2013:20:239-47. https://doi.org/10.1128/CVI.00580-12.

12. Cusi MG, Martorelli B, Di Genova G, Terrosi C, Campoccia G, Correale P. Age related changes in $T$ cell mediated immune response and effector memory to Respiratory Syncytial Virus (RSV) in healthy subjects. Immun Ageing. 2010;7:14. https://doi.org/10.1186/1742-4933-7-14

13. van Essen GA, Beran J, Devaster J-M, Durand C, Duval X, Esen M, et al. Influenza symptoms and their impact on elderly adults: randomised trial of AS03-adjuvanted or non-adjuvanted inactivated trivalent seasonal influenza vaccines. Influenza Other Respir Viruses. 2014;8:452-62. https:// doi.org/10.1111/irv.12245.

14. Couch RB, Bayas JM, Caso C, Mbawuike IN, López CN, Claeys C, et al. Superior antigen-specific CD4 ${ }^{+}$T-cell response with ASO3adjuvantation of a trivalent influenza vaccine in a randomised trial of adults aged 65 and older. BMC Infect Dis. 2014;14:425. https://doi. org/10.1186/1471-2334-14-425.

15. Parodi V, de Florentiis D, Martini M, Ansaldi F. Inactivated influenza vaccines: recent progress and implications for the elderly. Drugs Aging. 2011;28:93-106. https://doi.org/10.2165/11586770-000000000-00000.

16. Falsey AR, Treanor JJ, Tornieporth N, Capellan J, Gorse GJ. Randomized, double-blind controlled phase 3 trial comparing the immunogenicity of high-dose and standard-dose influenza vaccine in adults 65 years of age and older. J Infect Dis. 2009;200:172-80. https://doi.org/10.1086/599790.

17. Levin MJ, Smith JG, Kaufhold RM, Barber D, Hayward AR, Chan CY, et al. Decline in varicella-zoster virus (VZV)-specific cell-mediated immunity with increasing age and boosting with a high-dose VZV vaccine. J Infect Dis. 2003;188:1336-44. https://doi.org/10.1086/379048.

18. Fleming DM, Taylor RJ, Lustig RL, Schuck-Paim C, Haguinet F, Webb DJ, et al. Modelling estimates of the burden of respiratory syncytial virus infection in adults and the elderly in the United Kingdom. BMC Infect Dis. 2015;15:443. https://doi.org/10.1186/s12879-015-1218-z.

19. Kurzweil V, Tang R, Galinski M, Wang K, Zuo F, Cherukuri A, et al. Translational sciences approach to RSV vaccine development. Expert Rev Vaccines. 2013;12:1047-60. https://doi.org/10.1586/14760584.2013.82470 6.

20. McElhaney JE, Xie D, Hager WD, Barry MB, Wang Y, Kleppinger A, et al. T cell responses are better correlates of vaccine protection in the elderly. J Immunol. 2006;176:6333-9.

21. Falloon J, Ji F, Curtis C, Bart S, Sheldon E, Krieger D, et al. A phase 1a, first-in-human, randomized study of a respiratory syncytial virus $F$ protein vaccine with and without a toll-like receptor-4 agonist and stable emulsion adjuvant. Vaccine. 2016;34:2847-54. https://doi.org/10.1016/j.vacci ne.2016.04.002

22. Falloon J, Talbot HK, Curtis C, Ervin J, Krieger D, Dubovsky F, et al. Dose selection for an adjuvanted respiratory syncytial virus $F$ protein vaccine 
for older adults based on humoral and cellular immune responses. Clin Vaccine Immunol. 2017;24:e00157. https://doi.org/10.1128/cvi.00157-17.

23. Tanner SD, Bandura DR, Ornatsky O, Baranov VI, Nitz M, Winnik MA. Flow cytometer with mass spectrometer detection for massively multiplexed single-cell biomarker assay. Pure Appl Chem. 2008;80:2627-41. https:// doi.org/10.1351/pac200880122627.

24. Patton K, Aslam S, Shambaugh C, Lin R, Heeke D, Frantz C, et al. Enhanced immunogenicity of a respiratory syncytial virus (RSV) F subunit vaccine formulated with the adjuvant GLA-SE in cynomolgus macaques. Vaccine. 2015;33:4472-8. https://doi.org/10.1016/j.vaccine.2015.07.025.

25. Finck R, Simonds EF, Jager A, Krishnaswamy S, Sachs K, Fantl W, et al. Normalization of mass cytometry data with bead standards. Cytometry A. 2013;83:483-94. https://doi.org/10.1002/cyto.a.22271.

26. Ross TM, Lin CJ, Nowalk MP, Huang H-H, Spencer SM, Shay DK, et al. Influence of pre-existing hemagglutination inhibition titers against historical influenza strains on antibody response to inactivated trivalent influenza vaccine in adults 50-80 years of age. Hum Vaccines Immunother. 2014;10:1195-203. https://doi.org/10.4161/hv.28313.

27. He X-S, Holmes TH, Sasaki S, Jaimes MC, Kemble GW, Dekker CL, et al. Baseline levels of influenza-specific CD4 memory T-cells affect T-cell responses to influenza vaccines. PLoS ONE. 2008;3:e2574. https://doi. org/10.1371/journal.pone.0002574.

28. O'Connor J-E, Herrera G, Martínez-Romero A, de Oyanguren FS, Díaz L, Gomes A, et al. Systems Biology and immune aging. Immunol Lett. 2014;162(1 Pt B):334-45. https://doi.org/10.1016/j.imlet.2014.09.009.

29. Fourati S, Cristescu R, Loboda A, Talla A, Filali A, Railkar R, et al. Pre-vaccination inflammation and B-cell signalling predict age-related hyporesponse to hepatitis B vaccination. Nat Commun. 2016;7:10369. https:// doi.org/10.1038/ncomms10369.

30. Mather M, Jacobsen LA, Pollard KM. Aging in the United States. Popul Bull. 2015;70:1-8.
Ready to submit your research? Choose BMC and benefit from:

- fast, convenient online submission

- thorough peer review by experienced researchers in your field

- rapid publication on acceptance

- support for research data, including large and complex data types

- gold Open Access which fosters wider collaboration and increased citations

- maximum visibility for your research: over $100 \mathrm{M}$ website views per year

At BMC, research is always in progress.

Learn more biomedcentral.com/submissions 